\title{
Organização do trabalho, sintomatologia dolorosa e significado de ser portador de LER/DORT
}

\author{
Labor organization, painful symptomatology and meaning \\ of being a RSI/WRMD holder
}

\author{
Elizabeth Navas Sanches ${ }^{[a]}$, Luiz Roberto Agea Cutolo ${ }^{[\mathrm{b}]}$, \\ Pamela Soares $^{[c]}$, Rosana Marques da Silva ${ }^{[\mathrm{d}]}$
}

[a] Psicóloga, Doutora em Engenharia de Produção, Universidade Federal de Santa Catarina (UFSC), Universidade do Vale do Itajaí, Itajaí, SC - Brasil, e-mail: beth@univali.br

[b] Médico, Doutor em Educação pela Universidade Federal de Santa Catarina (UFSC), Itajaí, SC - Brasil.

[c] Acadêmica do curso de Psicologia, Universidade do Vale do Itajaí (UNIVALI), Itajaí, SC - Brasil.

[d] Psicóloga, Mestre em Engenharia de Produção e Sistemas: Qualidade e Produtividade, Universidade Federal de Santa Catarina (UFSC), Universidade do Vale do Itajaí (UNIVALI), Itajaí, SC - Brasil.

\section{Resumo}

As Lesões por Esforço Repetitivo (LER) ou os Distúrbios Osteomusculares Relacionados ao Trabalho (DORT) expressam os efeitos advindos da realização de atividades profissionais do trabalhador contemporâneo, transformados em dor e sofrimento. Essas nomenclaturas representam inúmeras doenças, como tenossinovites e tendinites. Na atualidade, essas lesões tornaramse comuns e estão relacionadas às várias funções, todas com algo em comum: o sobreuso das extremidades do corpo, principalmente as superiores, com sintomas complexos e mal definidos e com sua subjetividade referida por cada paciente. Este estudo teve como objetivo investigar os fatores da organização do trabalho bem como da sintomatologia dolorosa, além do significado de ser portador de LER/DORT em integrantes de uma associação de portadores em um município de Santa Catarina. Trata-se de um estudo exploratório, descritivo, cuja amostra foi delimitada por saturação dos dados, representada por oito portadores daquela associação. $O$ instrumento utilizado foi um roteiro de entrevista semiestruturado e os dados foram analisados tendo como base os pressupostos da análise de conteúdo temático da fala dos interlocutores. Os resultados obtidos trouxeram, à compreensão, os fatores da organização do trabalho que favoreceram o desenvolvimento ou o agravamento das LER/DORT, as causas que interferiram na saúde do 
trabalhador e que resultaram no sofrimento dos pesquisados, a história da dor, a dificuldade para a obtenção de um diagnóstico claro e preciso, e as consequências pessoais, sociais e profissionais de ser portador de tais sequelas.

Palavras-chave: Saúde do trabalhador. Condições de trabalho. Transtornos traumáticos cumulativos.

\begin{abstract}
Repetitive Strain Injuries (RSI) or Work-Related Musculoskeletal Disorders (WRMD) evidence the effects derived from the performance of professional activities carried out by the contemporaneous worker that result into pain and suffering. These nomenclatures represent numberless diseases, like tenosynovitis and tendinitis. Nowadays, these injuries have become ordinary and are related to several functions, all of them having in common the overuse of the body limbs, especially the upper ones, with complex and poorly defined symptoms while their subjectivity is referred by each patient. This study had the objective of investigating labor organization and painful symptomatology factors besides the meaning of being a RSI/WRMD holder among members of a society of holders in a municipality of Santa Catarina. It is an exploratory, descriptive study whose sampling was delimited by data saturation comprising eight holders of that society. The applied instrument was a script of semi-structured interview and the data underwent analysis based on the presuppositions of theme content analysis of the interviewees' speech. The obtained results allowed understanding the labor organization factors that favored the development or the aggravation of RSI/WRMD, the causes that interfered in the worker health and resulted into suffering of the investigated subjects, the pain history, the difficulty in obtaining a clear and accurate diagnosis and the personal, social and professional consequences of being holder of such sequelae.
\end{abstract}

Keywords: Occupational health. Working conditions. Cumulative trauma disorders.

\section{Introdução}

O trabalho carrega um duplo papel: ao mesmo tempo em que pode proporcionar o desenvolvimento dos indivíduos, elevar a expectativa e a qualidade da vida, ser fonte de sustento, favorecer a autorrealização e a valorização, quando realizado sob condições inadequadas, pode prejudicar a saúde, provocar doenças, encurtar a vida e até levar à morte. Segundo Schiling (1984), baseado no manual do Ministério da Saúde (Dias, 2001), o trabalho pode participar de três formas no desenvolvimento de patologias: como uma causa necessária; como um fator contributivo, mas não necessário; e como provocador de um distúrbio latente ou agravador de uma doença já estabelecida, como uma concausa. As estratégias de intensificação do trabalho e de controle dos trabalhadores, além de características individuais do trabalhador, podem colaborar no aparecimento e na evolução de doenças ocupacionais, dentre elas as LER/DORT, nas quais se entrelaçam diversos fatores causais, como atividades mecânicas por períodos de tempo prolongados, fatores da organização do trabalho, dentre outros (Dias, 2001; Mendes, 1995).

As Lesões por Esforço Repetitivo (LER) ou Distúrbios Osteomusculares Relacionadas ao Trabalho (DORT) são nomenclaturas para representar inúmeras doenças, como tenossinovites e tendinites. $\mathrm{Na}$ atualidade, essas enfermidades alcançam grandes proporções e as mais variadas funções ocupadas pelos diversos profissionais, todos com algo em comum: o sobreuso das extremidades do corpo, principalmente as superiores, com sintomas complexos e mal definidos e com subjetividade de sintomas referidos por paciente (Heloani; Capitão, 2003; Maciel; Fernandes; Medeiros, 2006; Monteiro, 1997). O ônus do aumento da produtividade recaiu sobre os trabalhadores; para estes, as exigências ultrapassam os limites da resistência psíquica e biológica do homem, repercutindo também no plano individual (Codo \& Almeida, 1995; Maciel et al., 2006).

Antes do século XIX, as LER/DORT atingiam um pequeno número de pessoas, principalmente as que trabalhavam com a escrita. $\mathrm{Na}$ Revolução Industrial, com a substituição da pena de 
ave pela de aço, tornando o trabalho mais rápido, os casos de LER aumentaram. Com o desenvolvimento do telégafro e o nascimento da categoria de telegrafista, os casos cresceram e se propagaram para duas outras categorias: os mecanógrafos/datilógrafos e os telefonistas. Nos anos 80 , essa doença assumiu status epidêmico, coincidindo com a intensa renovação tecnológica, as mudanças da organização do trabalho e a modernização do trabalho. Nesse contexto, as LER/DORT deixaram de ser um modo de adoecimento de poucas categorias, tornando-se um grave problema do trabalho, social e de saúde pública (Barros \& Guimarães, 1999).

No Brasil, a história das LER/DORT começa a ser notificada na classe dos bancários no início dos anos 80, e logo estas doenças são propagadas aos escriturários, indústrias metalúrgica, química e de montagem eletroeletrônica, caixas de supermercado e embaladores. Passam, na década de 90, juntamente com a surdez, a ser as doenças do trabalho mais notificadas e as que demandam mais aos serviços de saúde do trabalhador (Monteiro, 1997).

São definidas como patologias que acometem os músculos, os tendões e os vasos, degenerando os tecidos e provocando lesões ou inflamações, acontecendo quando o ritmo da lesão ultrapassa a velocidade de recuperação dos tecidos da região. Constituem-se como uma soma de esforços e traumas repetitivos com grande intensidade, caracterizada por dor crônica e afecções, de forma isolada ou associada, com ou sem degeneração dos tecidos, afetando principalmente, mas não apenas, os membros superiores, região escapular e pescoço. Seu aparecimento e sua evolução são de caráter insidioso, com origem multifatorial complexa, entrelaçando-se vários fatores causais (Codo \& Almeida, 1995; Couto, 1995; Dias, 2001; Heloani \& Capitão, 2003; Lech Hoefel, Severo \& Pitagoras, 1998; Merlo \& Jacques; Hoefel, 2001; Silva \& Másculo, 2002).

Contribui para o seu surgimento a execução de algumas tarefas como: repetição de movimento, esforço físico, pressão mecânica, vibração, ritmo de trabalho acelerado, invariabilidade, monotonia de tarefas, trabalho muscular estático, choques, retraimento de tensões, ausência de intervalos de descanso, aspectos ambientais, posturas e movimentos inadequados mantidos por tempo prolongado (Ghisleni \& Merlo, 2005; Limongi-França \& Rodrigues, 1999; Maciel et al., 2006; Merlo et al., 2001; Silva \& Másculo, 2002).
Essas doenças vêm se agravando pelo desconhecimento sobre sua patologia e ausência de intervenções ergonômicas nas condições de trabalho. Sua maior visibilidade deve-se ao aumento da frequência e da maior divulgação pela mídia e pelos sindicatos de trabalhadores das categorias (Dias, 2001; Silva \& Másculo, 2002).

O aspecto enigmático da doença é comprovado por duas questões que buscam ser respondidas para encontrar os fatores que a desencadeia: "por que certas doenças podem ora manifestar-se, ora permanecerem silenciosas?" e "por que todos os funcionários não adquirem a doença se esta é causada pelo esforço repetitivo?” (Barros \& Guimarães, 1999; Codó \& Almeida, 1995; Monteiro, 1997).

Dejours, Dessors e Desriaux (1993) dividem a organização do trabalho em: divisão das tarefas, em que alguns indivíduos definem por outros o trabalho a ser executado, os ritmos e o modo operatório; e divisão dos homens, a hierarquia, os níveis de supervisão e de comando que determinam as relações de trabalho.O espaço do trabalho exprime a identidade do indivíduo, sua personalização e também a individualidade da organização. Então, o trabalho em si não é nocivo e perigoso; o que o torna assim é a maneira que este é organizado pelo homem. No caso das LER/DORT, existe uma dimensão social, mais abrangente em sua determinação, a qual se compõe de duas dimensões indissociáveis: a internalidade do processo e organização do trabalho (dimensão do trabalho); e o modo de cada um sentir e refletir o mundo (dimensão individual) (Rocha, Rigotto \& Buschinelli, 1993).

Articulando essas duas dimensões, vários são os fatores associados às LER/DORT: biomecânicos, presentes nas atividades; psicossociais, relacionados à organização do trabalho; fatores ligados à psicodinâmica do trabalho ou aos desequilibrios psíquicos gerados em situações especiais de trabalho na origem do processo de adoecimento (Dias, 2001).

Como fatores de organização do trabalho, temos a realização de horas extras e pausas durante a jornada de trabalho, velocidade do trabalho, falta de material, encomendas extras, urgências, emergências, retrabalho, falta de pessoal e sobrecarga (Codo \& Almeida 1995; Couto, Nicoletti \& Lech, 1998), o que certamente determina mudanças na forma de distribuição e carga de trabalho aos trabalhadores.

A sintomatologia dolorosa caracteriza-se por ser mal localizada e com intensidade variável, 
mas com sinais e sintomas inflamatórios nas articulações. Em geral não são facilmente diagnosticadas. O primeiro sinal desse ciclo vicioso é a dor, leve ou moderada e sempre ligada ao movimento, passando a ser contínua, difusa e intensa, com períodos de exacerbação, caracterizando-se também por uma dor noturna e demorada, com a ocorrência de vários sintomas como formigamento, dormência, choque, sensação de peso e fadiga, levando o profissional a não realizar o trabalho para fugir do incômodo da dor. Os estágios mais severos são acompanhados de sinais e sintomas clínicos intensos, que envolvem parestesias e perda de força muscular. As dores podem ser tão frequentes e intensas que trabalhar sentindoas é tido pelo trabalhador como inerente ao próprio dia (Limongi-França \& Rodrigues, 1999). Monteiro (1997) revela que a doença traz consequências para o indivíduo em todos os aspectos, como no trabalho, no cotidiano, no autocuidado, nos relacionamentos interpessoais, favorecendo inseguranças, medos e angústias.

Dessa forma, ser portador de LER/DORT significa enfrentar a discriminação e a tristeza decorrentes do adoecimento, que surgem como uma ameaça da identidade do trabalhador, gerando humilhação, frustração, raiva, sofrimento, sentimento de culpa, dentre outros (Ghisleni; Merlo, 2005; Lima, Neves \& Pimenta, 2005).

Um programa efetivo de prevenção constitui-se no reconhecimento dos riscos, naidentificação, no ambiente de trabalho, dos fatores com potencial de dano, medidas adotadas para eliminação ou controle da exposição dos fatores de risco e proteção dos trabalhadores e recursos de vigilância em saúde e fiscalização do trabalho, objetivando identificar se o empregador cumpre suas obrigações quanto à identificação, à avaliação, à adoção de medidas corretivas de controle ambiental e de saúde do trabalhador. $\mathrm{O}$ plano de tratamento contempla desde a explicação para o paciente sobre a dor, orientação sobre posturas nas diversas atividades, utilização de medicamentos e de tratamentos com terapias ocupacionais, até a avaliação de desequilíbrios psíquicos, identificando formas precoces de seu aparecimento (Dias, 2001).

Considerando a relevância do estudo deste tema, este trabalho descreveu aspectos da organização do trabalho, como hora extra, sobrecarga, velocidade do trabalho, pausas, repetitividade e submissão ao poder; características da sintomatologia dolorosa, como história e consequências da dor; e o significado de ser portador de LER/DORT.

\section{Método}

A pesquisa realizada foi de caráter exploratório e descritivo, em uma associação de portadores de LER/DORT, situada em um município de Santa Catarina, fundada em 3 de janeiro de 2003, por 17 membros, todos portadores da doença, que se conheceram e se reuniam frequentemente para debater o assunto antes da criação da instituição. O principal objetivo da associação é lutar pela humanização do atendimento dado aos portadores de LER/DORT e buscar métodos de informação sobre a doença e os direitos dos portadores. Atualmente, conta com 481 associados, que contribuem com um valor mensal irrisório e dispõem de benefícios como convênios com médicos, advogados, farmácias, fisioterapeutas e clínicas.

Para a amostra inicial, foram definidos os seguintes critérios: ser portador de sintomas de LER/ DORT; estar afastado do trabalho para recuperação da saúde e ser membro da Associação de Portadores deLER/DORT. O critério de interrupção da amostra foi o da saturação dos dados.

O instrumento elaborado para a coleta de dados foi um roteiro de entrevista semiestruturado, permitindo a interação entre pesquisador e sujeito da pesquisa, otimizando a compreensão do que foi dito, valorizando as nuanças do discurso e o aprofundamento das categorias emergentes. As entrevistas foram individuais, tiveram duração aproximada de 45 minutos e foram realizadas de acordo com a conveniência dos sujeitos. As entrevistas ocorreram entre os meses de fevereiro e março de 2008, foram gravadas e posteriormente transcritas.

Os dados foram analisados de acordo com os pressupostos da Análise de Conteúdo Temático de Fala dos Interlocutoresm, seguindo os seguintes passos: leitura "horizontal" das transcrições, objetivando um entendimento global do material disponível; seleção das Unidades de Registro que pudessem permitir o aparecimento indutivo de categorias relevantes ao estudo; identificação das categorias; identificação de eventuais subcategorias; agrupamento ou classificação das categorias por aproximações temáticas; e análise inferencial do conjunto. Os temas e as categorias definidas foram analisados por sua aproximação 
temática, gerando agrupamentos ou classificações. O tema relacionado à organização do trabalho inclui as categorias hora extra, sobrecarga, pausa, velocidade do trabalho, repetitividade e submissão ao poder; o tema sintomatologia dolorosa é composto pelas categorias história e consequências da dor; e do tema significado de ser portador emergiram as categorias preconceito e tristeza.

Oprojeto foi registrado no Sistema Nacional de Informação sobre Ética em Pesquisa (SISNEP), submetido ao Comitê de Ética em Pesquisa da Universidade do Vale do Itajaí (UNIVALI), obtendo o parecer número 538/07, aprovado pela Associação de Portadores de LER/DORT. Foram garantidos aos sujeitos sigilo, anonimato, informações sobre os objetivos da pesquisa, direito de não participar ou desistir da pesquisa em qualquer fase e devolutiva para a associação ao término do trabalho.

\section{Resultados e discussáo}

\section{Caracterizaçáo dos sujeitos}

Foram entrevistados oito participantes, sendo seis do sexo feminino e apenas dois do sexo masculino. Couto (1995) e Maciel et. al. (2006) concordam que as mulheres têm de duas a três vezes mais risco de desenvolvimento de LER/DORT, por alguns fatores: sua estrutura física tem menor resistência (massa muscular, composição corporal e tamanho); os hormônios (principalmente estrógenos) acumulam líquidos nos tecidos e dificultam a melhoria nos casos de inflamação; e as atividades domésticas sobrecarregam os membros superiores. Monteiro (1997) observou a grande prevalência de mulheres acometidas pelas LER/DORT, resultante do processo de segregação que as coloca em tarefas específicas, repetitivas e monótonas.

A média de idade dos voluntários foi de aproximadamente 39 anos. O voluntário mais jovem tinha 25 anos e as duas participantes com mais idade apresentavam 45 anos. Macieletal. (2006) constataram em sua pesquisa que a faixa etária acometida pelas LER/DORT é de 20 a 39 anos, afastando do trabalho indivíduos numa fase produtiva, os quais acabam não contribuindo no desenvolvimento da economia e passam a depender de benefícios da Previdência Social.

Em relação à estrutura familiar, a maioria dos entrevistados é casado e tem apenas um filho.
O principal ramo de atividade foi o têxtil, sendo que cinco voluntários trabalham ou já trabalharam neste setor: um dos entrevistados trabalhou em duas empresas, ambas do ramo têxtil e com as mesmas funções. Quatro exercem atividades de costureira e uma como passadora. Uma entrevistada trabalha, atualmente, em um hospital como copeira, porém seu antigo emprego era no setor têxtil, como costureira. A principal atividade apontada por Maciel et al. (2006) em sua pesquisa foi a confecção de roupas. Esses autores constataram, também, que no trabalho em indústrias têxteis a postura necessária para a realização do trabalho influencia o desenvolvimento das LER/DORT, especialmente nas regiões da coluna vertebral e pernas. Couto (1995) discute a utilização das máquinas de costura e de objetos como alicates e tesouras, que podem contribuir para ocasionar tendinite da fascia palmar, tenossivite estenosante, lesões crônicas dos nervos e dificuldades para realizar as tarefas por anulação das extremidades comprometidas.

Dos outros três entrevistados, dois trabalham no setor de transportes, um como motorista, exercendo atividades de direção, carga e descarga de caminhão; um como servente, fazendo limpeza de ônibus; e o último em uma empresa metalúrgica, como montador de peças.

O tempo médio de trabalho na organização que ocasionou a doença somou seis anos, sendo que dois entrevistados tinham oito anos de trabalho e o mais jovem trabalha há sete meses na organização. Maciel et al. (2006) concluem, quanto ao tempo de trabalho na organização, que os indivíduos que exercem a mesma função há mais de seis meses têm aproximadamente três vezes mais chances de desenvolver LER/DORT.

\section{Os temas e suas categorias}

\section{Fatores da organizaçáo do trabalho}

A primeira categoria, realização de hora extra, representa mais queixas de dor, se comparada a indivíduos que não a realizam (Maciel et al., 2006). Os entrevistados declararam realizar entre três a nove horas extras por dia. Um dos participantes declarou a realização de hora extra também aos sábados, como pode ser observado nos relatos a seguir: 
A gente fazia bastante hora extra [...] tinha semana que era a semana toda [...] das 5 às 5 horas e às vezes tinha dia que ia das 5 horas até as 10 horas da noite (S3).

No comegro, toda a vida eu nunca me negava a fazer hora, chegava até as 10 da noite, sábado também [...] era por produção (S4).

Bem trabalhado [...] uma média de 3 a 4 horas por dia, até mais, às vezes (S5).

Para a categoria sobrecarga, emergiram as subcategorias: falta de material e de pessoal, encomendas extras e urgências. Observou-se que as respostas relativas a esta categoria implicam diretamente a realização de horas extras.

A falta de material foi relatada pelos trabalhadores como responsável pela realização de hora extra, troca dos funcionários nos setores das empresas, fator que pode se configurar como um aspecto positivo, já que a realização de trabalhos em outros setores evita o trabalho repetitivo: "se o material chega no dia, dai tem que fazer hora extra pra entregar o pedido" (S5).

A falta de pessoal apareceu nos relatos, trazendo como consequência a realização de hora extra:

Eles pedem pra gente ajudar, dai a gente cobre a falta, faz hora dai (na confecção) [...] quando faltava gente, a gente apurava [...] fazia hora, era obrigada (S1).

Tens que suprir aquele que falta, tem que dobrar o serviço (S5).

As encomendas extras e urgências refletem nas horas extras e na busca por terceirização: "É tudo com nós [...] quando é muito, assim que a gente não dá conta, a gente manda pra fora" (S2). "Tinha bastante encomenda com prazo curto [...], fazia bastante hora extra" (S8).

As encomendas extras e as urgências também trazem como consequência o trabalho num ritmo intenso e sob pressão, como pode ser verificado na categoria velocidade do trabalho:

Rápido era bem cobrado [...] era produção contadinha [...] eles contavam tudo [...] era bem cobrado (S1). Tenho que dar conta da cobertura, reta e uma Overlock [...] tenho que dar conta [...] até dar conta de acabar com tudo que tinha que fazer [...] era rápido, muita pressa. (S3).

Bempuxado, sabe, era produção [...] era rápido, muita pressão [...] a gente, na realidade, era como um robô (S4).
Tinha que fazer rápido, tinha que ser bem ágil, não podia fazer devagar [...] tinha um tanto, uma cota pra fazer, se não fizesse eles reclamavam (S6).

A quarta categoria, pausas, está diretamente relacionada ao desgaste dos trabalhadores. Os sujeitos da pesquisa relataram realizar menos pausas do que o recomendado pelo sindicato de sua categoria, as quais deveriam ser de 30 minutos nos períodos matutino e vespertino e uma hora de almoço. "Almoģo de 30 minutos, e tinha café na parte da tarde de 15 minutos (S4). Tomava um lanchinho, mais ou menos 15 minutos" (S6). Alguns entrevistados relataram realizar intervalo apenas quando faziam hora extra:

Uma hora de almoço e café quando a gente fazia hora extra era 15 min, senão a gente não tomava (S1).

Uma hora de almoço e 15 min de café a gente tinha só com hora extra (S5).

Parava pro café 15 minutos, de manhã e de tarde, mas de tarde só se dava ou se a gente i ficar pra fazer hora, senão não parava, e tinha o almoço de uma hora (S8).

A quinta categoria, repetitividade, é revelada nas falas que trazem a fragmentação do trabalho, consequência da velocidade exigida para que se cumpram os objetivos de produção: "Sópassar o dia inteiro passando" (S2). "É sempre igual" (S5).

A sexta categoria, relacionada aos fatores de organização do trabalho, foi denominada submissão ao poder. Embora as categorias hora extra, sobrecarga, repetitividade, pausas e velocidade do trabalho tenham trazido, de modo implícito, a submissão ao poder, evidencia-se a seguir, nas falas dos trabalhadores, a subordinação às regras organizacionais impostas verticalmente.

O poder pode ser utilizado como ferramenta para melhorias no funcionamento das organizações. Porém, muitas vezes, alguns supervisores maltratam os subordinados por meio de seu uso, transformando o ambiente de trabalho em um local desconfortável. Todavia, apesar de o supervisor tentar influenciar seus subordinados, é o comportamento do subordinado que torna esta influência eficaz ou não; ou seja, o poder envolve características individuais, pois a aceitação depende também da capacidade de avaliação do indivíduo (Hall, 1984). O medo alimenta a pressão, provocando a submissão às exigências por produção, refletindo na aceleração dos ritmos e na intensificação do esforço (Codo; Almeida, 1995; Spector, 2004). 
Era obrigada a fazer (S1).

Elas queriam assim, dai fazer ro que, né? [...] não, mas tu não pode escolber [...] Tá bom, né? Quem manda é a senhora [...] não podia pedir, não podia sair [...] ela contava (as peças produzidas) (S3).

Eu pedi pra trocar de lugar e eles nem ai [...] chorava direto [...] e eles nem aí (S4).

O conflito entre metas organizacionais e necessidades individuais é um grande agente estressor e contribuidor ao desenvolvimento das LER/ DORT. Isso porque as pressões organizacionais são por vezes muito poderosas e os indivíduos não têm liberdade para gerenciar suas atividades. Realizam horas extras com jornadas de trabalho extensas, atividades repetitivas em ritmos elevados de produção, acúmulo de funções, excesso de trabalho, inseridos em ambientes de trabalho inadequados e com falta de reconhecimento do trabalho realizado, ocasionando perda da identidade, estresse, esgotamento e insatisfação com o trabalho (Ghisleni \& Merlo, 2005; Limongi-França \& Rodrigues, 1999).

O trabalho realizado com o objetivo de produção acaba trazendo, consequentemente, a fragmentação. Guareschi e Grisci (1993) apontam que, quando são realizadas apenas "migalhas" do trabalho, o indivíduo acaba não tendo a visão total do processo, perdendo também o conhecimento sobre o que executa. Nesta dinâmica, torna-se alienado, sem fazer parte efetiva do processo de produção do produto, assumindo, para Guareschi (1988 apud Guareschi \& Grisci, 1993), características próprias da máquina.

As pausas são importantes, pois garantem a recuperação do físico e evitam a fadiga e a monotonia (Maciel etal., 2006). A fadiga se apresenta de dois tipos: a muscular (um acontecimento agudo que é sentido na musculatura) e a generalizada (uma sensação difusa, subjetiva de cansaço). Trata-se de uma diminuição na capacidade funcional de um organismo, ocasionando uma degradação em âmbito qualitativo do trabalho (Couto, 1995; Grandjean, 1998).

A fadiga provoca uma sobrecarga na utilização do órgão, sistema ou organismo, e também desgasta psiquicamente o trabalhador, que começa a simplificar sua tarefa (Couto, 1995). Uma de suas consequências é a monotonia, que seria uma reação do organismo a uma situação pobre em estímulos ou em condições com pequenas variações dos estímulos. Suas causas seriam as tarefas repetitivas com longa duração e com o mínimo grau de dificuldade, porém sem possibilidade de se desligar mentalmente do trabalho, com a obrigação de atenção permanente. Este processo expressa a dissociação entre mente e corpo e também entre trabalho e prazer, levando o trabalhador a realizar suas atividades por meio de coisas alheias ao seu interesse e à sua vontade (Guareschi \& Grisci, 1993). O trabalho por produção não permite que as pausas sejam respeitadas, exigindo dos indivíduos um trabalho mais rápido e sob pressão, consequentemente, sem intervalos e com maior influência para realização de horas extras.

Para Dejours e Abdoucheli (1994), as tarefas muito repetitivas sufocam os desejos e reprimem o funcionamento mental. Para prevenir a repetitividade, os autores destacam duas maneiras: por meio do alargamento do trabalho de modo horizontal, ou seja, acrescentando-se tarefas semelhantes para cada indivíduo, sem, no entanto, mudar a natureza do trabalho (como a utilização, por exemplo, de rotações periódicas); ou pelo enriquecimento do trabalho verticalmente, com a disponibilização de desafios e exigências de novas responsabilidades.

\section{Sintomatologia dolorosa}

A primeira categoria, história da dor, foi estabelecida pela fala comum dos entrevistados terem trilhado um longo caminho até a comprovação do diagnóstico. A maior parte dos indivíduos sentia dores, mas não possuía um diagnóstico, mostrando a distância entre a dor e a obtenção do diagnóstico: "A dor comecou faz uns seis anos" (S3). "Dez anos que eu já sinto dor [...] três anos que eu tenho o laudo" (S5). "Sinto a dor desde 2004/2005" (S7).

Para Monteiro (1997), o diagnóstico das LER/DORT é um processo longo e tardio e as dores são invisíveis aos terceiros. Sendo assim, os sujeitos continuam sofrendo as pressões sociais, como pode ser observado no relato a seguir:

Ia nos médicos e eles não sabiam o que que eu tinha [...] fui em tantos médicos em um ano, e ninguém sabia o que en tinha, dai en voltei a trabalhar (S4).

Passei por vários médicos e ninguém sabia o que era [...] fiz uma perícia, mas depois voltei pro trabalho [...] não sabia o que era [...] não dá tanta bola pra dor, mas depois pioron (S7).

A segunda categoria foi denominada consequências da dor. A doença modifica todo o estilo 
de vida do portador e de sua família. O indivíduo doente traz não apenas a patologia, mas os problemas originários desta, como limitações na vida diária e destruição de projetos de vida (Codo \& Almeida, 1995). Observam-se, nas falas dos entrevistados, vários tipos de consequências na vida dos portadores, como limitações no cotidiano:

Não faço comida [...] não lavo a louça, não varro (S1). Não passo cera no chão (S2).

Não consigo fazer quase nada, en lavo uma louça [...] lavar uma roupa [...] pra estender a roupa dói os braços, pra carregar balde [...] tomando direto remédio, e não passa (S6).

Uma entrevistada relatou algo que foi classificado como limitação no autocuidado, dizendo não poder "nem pentear o cabelo" (S1), relatando que quando seu filho ou vizinha não estão em casa para ajudá-la, é preciso buscar outros meios, como a utilização de chapéus.

Outro entrevistado relatou se sentir "excluida [...], isolada em casa" (S8), dizendo que não fala com ninguém, apresentando evidências de limitações em seus relacionamentos, o que acaba trazendo consequências para sua vida social.

Codo e Almeida (1995) e Lech et al. (1998) destacam a importância da realização de um diagnóstico amplo, o mais completo, correto e efetivo possível. Como uma das principais características da doença é a invisibilidade, o meio mais eficaz para a realização do diagnóstico, buscando promover ações mais efetivas para o tratamento e permitindo uma conduta mais diretiva e humana aos indivíduos, deve envolver três abordagens: a doença, o trabalhador e o trabalho. Ou seja, devem estar interligados o diagnóstico clínico, o psicológico e o organizacional.

A doença afeta tanto o trabalho como o lar, já que o indivíduo se sente incapaz, trazendo o sofrimento tanto pela incapacidade de trabalho, como por não poder ser provedor de seu lar (Monteiro, 1997). Sabe-se que a sociedade estimula pessoas sadias e produtivas. Ao assumiro papel de doente, o indivíduo se afasta de suas atividades usuais, distanciando-se da família e dos amigos, renunciando, mesmo que temporariamente, ao seu papel social. O afastamento do trabalho e a falta de um diagnóstico acompanham muitos medos, inseguranças e angústias. O indivíduo passa a temer o fato de não ter condições para voltar a trabalhar e ser produtivo, sente-se triste e sem esperança, pois não vê melhoras em seu quadro e não tem mais o que almejar profissionalmente. Por não ter mais condições de retorno ao trabalho, teme a manutenção ou ruptura de suas relações socias, não sabendo o que os outros pensarão e como irão reagir a esta situação (Monteiro, 1997).

\section{Significado de ser portador}

A primeira categoria, preconceito, ressalta que a doença, na maioria das vezes, é mal vista na sociedade, sendo um aspecto importante a discriminação enfrentada pelo indivíduo portador de LER/ DORT, pois a identidade do trabalhador está ligada à busca pelo reconhecimento social de uma pessoa (Limongi-França \& Rodrigues, 1999). vadio (S5).

Tem gente que olha pra mim [...] acha que é um

É bem difícil [...], os outros olham, acham que a gente não quer trabalhar [...] olha assim pra mim, eu não tenho nada (S6).

Se sente um estorvo, passa por malandro [...] me sinto humilhado [...] ficarparado pra quem trabalhou a vida toda é horrivel (S7).

Passa por aproveitadores na empresa [...] como se a gente só quisesse ganhar o benefício [...] parece que a gente é malandra [...] os outros ainda duvidam (S8).

A segunda categoria, tristeza, é decorrente do adoecimento, que surge como um ameaçador da identidade do trabalhador, tendo como consequência a diminuição das possibilidades de criatividade, baixa autoestima e sentimento de que seu esforço não é socialmente reconhecido, ocasionando frustração, raiva e sofrimento (Ghisleni \& Merlo, 2005; Lima, Neves \& Pimenta, 2005).

Eu fiquei com depressão [...] a gente fala que tá com dor, mas eles não acreditam (S1).

Fica triste porque não dá pra volta pro trabalho (S2). Eu parei de trabalhar, é a pior coisa que tem [...] a única coisa era chorar [...] só chorava, uma tristęa [...] minha esperança é voltar pra costura (S3).

Fico triste, não quero ficar sem trabalhar (S8).

Saúde e doença têm seu conceito embasados em estruturas sociais. A doença transcende o 
doente, pois surge como uma ameaça ao equilíbrio orgânico e social. Por este motivo, o homem luta contra ela, já que, além de afetar suas relações, cria ansiedade e medo, pois é um choque para o qual a pessoa não estava preparada. Dentro do contexto de desconfianca e falta de confirmação do diagnóstico no qual está inserido o portador, este se sente pressionado para uma recuperação rápida e manifesta medo de não poder voltar ao trabalho, impedindo o reconhecimento de si mesmo e desestruturação de sua identidade. Algo definido por Codo e Almeida (1995) como "ideologia da culpabilização", em que a responsabilidade recai sobre os trabalhadores, deslocando a atenção de seu verdadeiro produtor.

$\mathrm{O}$ indivíduo, que anteriormente via e se identificava nos outros, sente o afastamento, levando à negação e à busca por ocultar a dor, pois, infelizmente, entre os primeiros sintomas das LER/ DORT e o autoconhecimento do adoecido, há um espaço de tempo que leva o indivíduo a processar e viver em seu sofrimento. Neste processo, sentese culpado, perde a autoestima, ressente-se com as incriminações e sofre pelo seu maior temor: a morte social (Monteiro, 1997).

Heloani e Capitão (2003) afirmam que o sofrimento no trabalho é consequência da organização do trabalho, dos aspectos que moldam a percepção e possibilidades de apreensão do indivíduo. O processo de adoecimento é específico para cada indivíduo, pois envolve sua história de vida e de trabalho, trazendo como consequências a incapacitação profissional e a destruição de projetos de vida. Portanto, é preciso que se busquem novos referenciais para que o indivíduo possa se reconhecer e ter a oportunidade de reorganizar sua história e de construir um novo projeto de futuro (Codo, Sampaio \& Hitomi, 1993; Ghisleni \& Merlo, 2005; Lima et al., 2005).

Diante do que foi exposto, percebe-se que os achados deste trabalho vão ao encontro de outros estudos nesta área do conhecimento, reforçando os aspectos da organização do trabalho que estão associados ao desenvolvimento das LER/DORT e de como estes portadores são afetados tanto em sua vida profissional como em seu cotidiano e em suas relações sociais. Tal processo desestrutura a identidade do indivíduo doente e faz com que este se sinta impotente diante dos outros e de si mesmo.

Ainda é interessante notar como os temas e as categorias encontradas, de certa forma, despertam uma visualização relativamente clara do fluxo hierárquico de causalidade. A Saúde do Trabalhador é um campo da Saúde Coletiva que parte do pressuposto da determinação social. Lembra-se que, num fluxo de causalidade, a determinação social aparece como regulador essencial dos processos de adoecimento. A essa determinação social se submetem os condicionamentos ecológico-ambientais e esses estimulam a patogênese observada pelos desencadeadores biológicos (Figura 1).

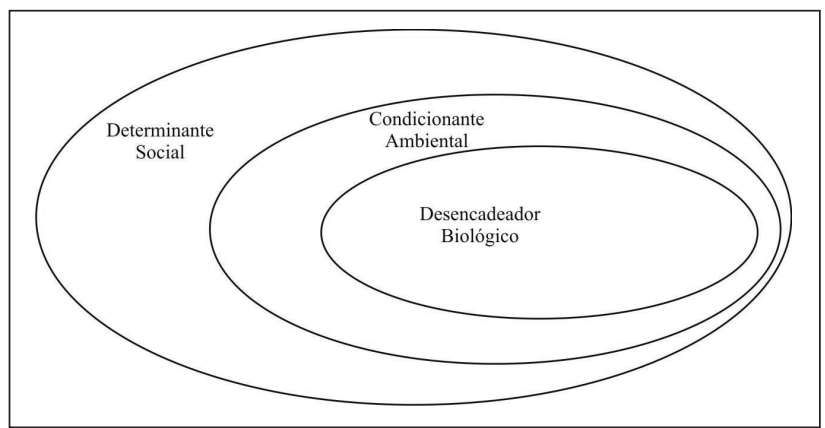

Figura 1 - Representação de relação causal do processo saúde-doença

Fonte: Cutolo, 2006.

Poder-se-ia afirmar que, no âmbito da determinação, o modo de produção capitalista leva à exploração do trabalho, à precarização do trabalho, à alienação, à produção e a sindicatos pouco atuantes. Como condicionantes, ter-se-ia a repercussão clara na coação, medo, pressão, exploração e submissão a que são submetidos os trabalhadores, sujeitos a horas extras, ausência de pausas, sobrecarga e repetição. Os desencadeadores biológicos seriam os esforços musculares e tendinosos repetitivos, culminando com o aparecimento da entidade nosológica LER/ DORT. Por último, poder-se-ia afirmar que a doença acaba por repercutir na vida social desses indivíduos. Sentimentos de baixa autoestima, exclusão, incapacidade funcional para tarefas cotidianas, preconceito (pois é visto como preguiçoso), humilhação, tristeza, frustração, raiva, sofrimento, sentimento de culpa, dentre outros, conforme representado na Figura 2. 


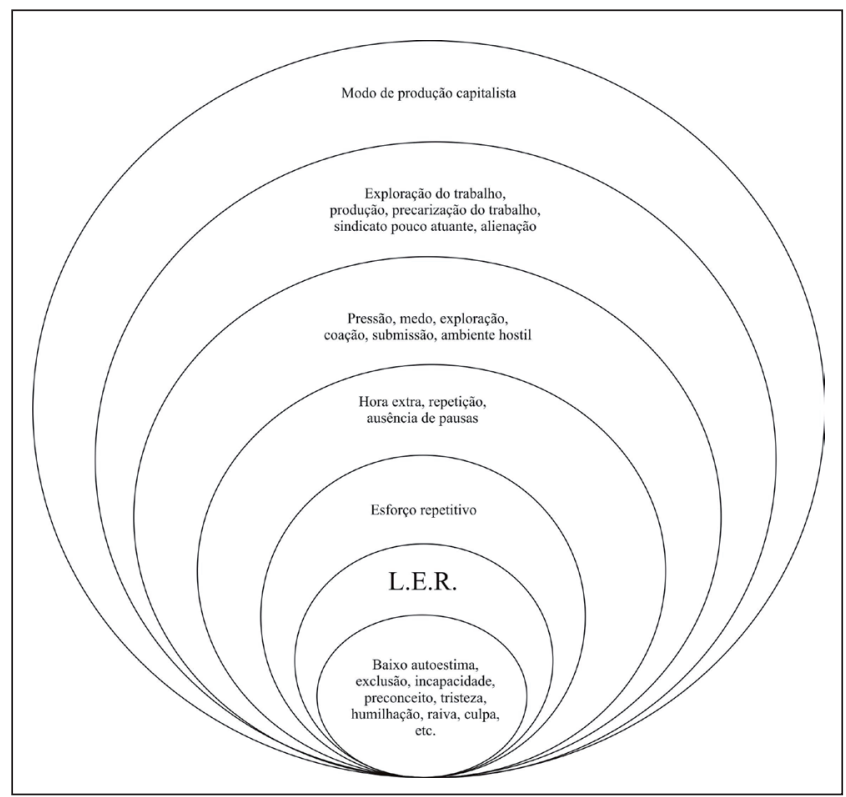

Figura 2 - Representação de relação causal do processo saúde-LER

Fonte: Entrevistas realizadas com portadores de LER/ DORT, 2008.

\section{Consideraçóes finais}

A realização desta pesquisa surgiu do interesse pelo estudo das LER/DORT e pela tentativa de compreender a percepção de portadores sobre esta doença de origem multicausal que vem ganhando cada vez mais destaque no contexto atual.

Foi possível conhecer, neste grupo de sujeitos, a relação entre o desenvolvimento das atividades profissionais e a dor, o que permitiu concluir que algumas atividades e modo de realização de tarefas contribuem para o desenvolvimento das LER/ DORT e que, quando realizadas dentro de algumas circunstâncias, estas atividades podem influenciar o surgimento ou agravo destas doenças.

Quanto aos fatores de organização do trabalho associados às LER/DORT, constatou-se que a realização de hora extra é algo recorrente no relato dos participantes, sendo utilizada como solução, pelos empregadores, para problemas como retrabalho, sobrecarga, encomendas extras, urgências, falta de material e de pessoal. A repetitividade também aparece como variável da organização do trabalho, favorecendo o surgimento da doença e abordando questões como a fragmentação do trabalho para alcance dos objetivos de produção e conclusão das metas estabelecidas, assim como evidencia a questão do poder organizacional. Outras variáveis, como o reduzido número de pausas e a velocidade para alcance das metas de produção, foram citadas nos fatores de organização do trabalho e também trazem como consequência a realização de horas extras. Em relação à velocidade do trabalho, a cobrança, a pressão e a imposição, mesmo que indiretamente, do poder organizacional confirmam os achados da literatura.

A influência da doença no cotidiano dos portadores foi investigada, permitindo a conclusão de que a doença traz as mais diversas consequências para os indivíduos portadores de LER/DORT, pois impõe limitações em seu dia a dia e cobra deles uma reestruturação de suas identidades e uma aceitação da incapacidade para realização de algumas atividades. Aspecto que aparece também é a tristeza, por não conseguirem mais suprir as expectativas sociais e pessoais e o sofrimento por que passam, mesmo que este não seja consciente, por perderem ou estarem ameaçados de perder sua identidade como seres produtivos. Também caracterizam a percepção que estes portadores têm de si e do mundo o preconceito enfrentado por não corresponderem mais ao que antes lhes era comum realizar, por terem medo de enfrentar essa situação sem um diagnóstico preciso e aceito, por não saberem o que os outros concluem de sua situação e como o estão vendo, e a pressão interna e externa pela recuperação rápida para voltar a trabalhar.

No que diz respeito à manutenção da saúde, existe um profundo desconhecimento por parte dos trabalhadores entrevistados dos meios disponíveis para a promoção da saúde e prevenção de doenças. Está na prevenção o sucesso para o início de qualquer atitude no sentido de minimizar a problemática das LER/DORT. No entanto, por trás da relação saúde-doença está o poder, que é registrado desde a história da humanidade e usado também como um instrumento de dominação (Barros \& Guimarães, 1999). Foi possível identificar que a submissão ao imposto pela organização em termos de ritmo, pausa, horas extras, alcance de metas e outras variáveis já mencionadas agrava a doença, estando o poder implícito em todas elas.

Espera-se que esta pesquisa venha a contribuir para as pessoas que trabalham no processo de diagnóstico e atendimento aos portadores de 
LER/DORT, para que estejam cientes da invisibilidade que a doença traz e do sofrimento ao qual o indivíduo está submetido. Pretende-se despertar as organizações, para que elas busquem ser um fator equilibrante na vida de seus colaboradores e para que medidas de prevenção possam ser estudadas e adotadas, com o objetivo principal de prevenir doenças como as LER/DORT e contribuir para melhor qualidade de vida no trabalho. Aos portadores, objetiva-se que tenham mais conhecimento sobre sua doença, sobre a contribuição do trabalho exercido no desenvolvimento ou agravo da dor e as consequências da doença, fatos que, muitas vezes, não são percebidos.

Como sugestões, recomendam-se um estudo mais aprofundado sobre os outros fatores considerados associados à sintomatologia dolorosa; a realização de um estudo com os familiares dos portadores, para maior conhecimento das consequências e da convivência com o portador; e um estudo aprofundado sobre os graus de dor dos portadores.

\section{Referências}

Barros, C. A. de, \& Guimarães, L. A. M. (1999). Lesões por Esforços Repetitivos, L.E.R.: Aspectos psicológicos. In L. A. M. Guimarães \& S. Grubits. Saúde mental e trabalho. São Paulo: Casa do Psicólogo.

Dias, E. C. (2001). Doenças relacionadas ao trabalho: Manual de procedimentos para os serviços de saúde. Brasília: Ministério da Saúde do Brasil.

Codo, W., \& Almeida, M. C. C. G. (1995).L.E.R. diagnóstico, tratamento e prevenção: Uma abordagem interdisciplinar. Petrópolis: Vozes.

Codo, W., Sampaio, J. J. C., \& Hitomi, A. H. (1993). Indivíduo, trabalho e sofrimento: Uma abordagem interdisciplinar. Petrópolis: Vozes.

Couto, H. de A. (1995). Ergonomia aplicada ao trabalho: $\mathrm{O}$ manual técnico da máquina humana. Belo Horizonte: Ergo.
Couto, H. de A., Nicoletti, S. J., \& Lech, O. (1998). Como gerenciar a questão das LER/DORT: Lesões por esforço repetitivo, distrúbios osteomusculares relacionados ao trabalho. Belo Horizonte: Ergo.

Cutolo, L. R. A. (2006). Modelo Biomédico, reforma sanitária e a educação pediátrica. Revista On-line da Associação Catarinense de Medicina, 35(4), 16-24.

Dejours, C., \& Abdoucheli, E. (1994). Psicodinâmica do trabalho: Contribuições da escola dejouriana à análise da relação prazer, sofrimento e trabalho. São Paulo: Atlas.

Dejours, C., Dessors, D., \& Desrlaux, F. (1993). Por um trabalho, fator de equilíbrio. Revista de Administração de Empresas, 33(3), 98-104.

Ghisleni, A. P., \& Merlo, Á. R. C. (2005). Trabalhador contemporâneo e patologias por hipersolicitação. Psicologia: Reflexão e Crítica, 18(2). Recuperado em 24 abr. 2007, em www.scielo.br

Guareschi, P. A., \& Grisci, C. L. I. (1993). A fala do trabalhador. Petrópolis: Vozes.

Grandjean, E. (1998). Manual de ergonomia: Adaptando o trabalho ao homem. Porto Alegre: Artes Médicas.

Hall, R. H. (1984). Organizações: Estrutura e processos. Rio de Janeiro: Prentice Hall do Brasil.

Heloani, J. R., \& Capitão, C. G. (2003). Saúde mental e psicologia do trabalho. São Paulo Perspectiva, 17(2). Recuperado em 2 mar. 2007, em www.scielo.br.

Lech, O., Hoefel, M. da G., Severo, A., \& Pitagoras, T. (1998). Aspectos Clínicos dos Distúrbios OsteoMusculares Relacionados ao Trabalho (DORT) (Lesões por Esforços Repetitivos). Belo Horizonte: Ergo.

Lima, M. A. G., Neves, R., Sá, S., \& Pimenta, C. (2005). Atitude frente à dor em trabalhadores de atividades ocupacionais distintas: uma aproximação da psicologia cognitivo-comportamental. Ciência e Saúde Coletiva, 10(1). Recuperado em 24 abr. 2007, em http://www.scielo.br 
Limongi-França, A. C., \& Rodrigues, A. L. (1999). Stress e trabalho: Uma abordagem psicossomática. São Paulo: Atlas.

Maciel, Á. C. C., Fernandes, M. B., \& Medeiros, L. S. (2006). Prevalência e fatores associados à sintomatologia dolorosa entre profissionais da indústria têxtil. Revista Brasileira de Epidemiologia, 9(1). Recuperado 19 abr. 2007, em http://www.scielo.br

Mendes, R. (1995). Patologia do trabalho. Rio de Janeiro: Atheneu.

Merlo, A. R. C., Jacques, M. da G. C., \& Hoefel, M. da G. L. (2001). Trabalho de grupo com portadores de LER/DORT: Relato de experiência. Psicologia Reflexão Crítica, 14(1). Recuperado em 2 jun. 2007, em http://www.scielo.br

Monteiro,J. C. Lesões por esforços repetitivos: um estudo sobre a vivência do trabalhador portador de L.E.R. 1997. Dissertação de Mestrado, Departamento de Engenharia de Produção e Sistemas da Universidade Federal de Santa Catarina, Florianópolis. Recuperado em 2 jun. 2007, em http:// www.ppgep.ufsc.br.

Rocha, L. E., Rigotto, R. M., \& Buschinelli, J. T. P. (1993). Isto é trabalho de gente? Vida, doença e trabalho no Brasil. Petrópolis: Vozes.

Silva, G. W., \& Másculo, F. S. (2002). LER: Epidemia silenciosa que causa reflexos na saúde dos bancários. Trabalho Completo apresentado no II Conference on Occupational and Environmental Health - Integrating the Americas. Salvador: Autor.

Spector, P. E. (2004). Psicologia nas organizações. São Paulo: Saraiva.

Recebido: 25/06/2009

Received: 06/25/2009

Aprovado: 16/09/2009

Approved: 09/16/2009 